\title{
OCUPACIONES HUMANAS HOLOCÉNICAS EN ABRIGOS ROCOSOS DE LA PUNA DE SALTA
}

\author{
Gabriel López ${ }^{1}$, Federico Coloca ${ }^{2}$ y Juan Pablo Orsi ${ }^{2}$ \\ ${ }^{1}$ CONICET, Instituto de Arqueología ${ }^{2}$ Facultad de Filosofía y Letras, UBA
}

\section{Introducción}

En este trabajo se resumen brevemente las investigaciones recientes desarrolladas en abrigos rocosos en distintas áreas de la Puna de Salta, Argentina. Al respecto, es relevante destacar la escasez de refugios bajo roca en las tierras altas puneñas, por lo cual la presencia de estos sitios es importante para analizar la diversidad arqueológica y el cambio cultural a lo largo del Holoceno en la región. En este sentido, se reconoce que en general la preservación arqueológica en capa es muy buena en estos contextos.

La información principal proviene de tres sitios arqueológicos ubicados en tres áreas de la Puna de Salta: Pastos Grandes, Ratones y Pocitos (Figura 1). Estas áreas se ubican próximas entre sí, a una altura promedio de $4000 \mathrm{msnm}$.

El poblado de Pastos Grandes se ubica a $60 \mathrm{~km}$ al suroeste de San Antonio de los Cobres, en el marco de una extensa vega conformada por las aguas de deshielo de los nevados de Pastos Grandes en dirección Norte. En las quebradas ubicadas en este sector se encuentra el sitio Alero Cuevas, detectado en la campaña del año 2004 dentro de una investigación de doctorado (López 2008). Este sitio registra una larga secuencia de ocupaciones humanas.

Por su parte, el salar de Ratones se ubica a alrededor de $70 \mathrm{~km}$ del poblado de Pastos Grandes, en dirección Sur. Allí se registró el sitio Cueva Inca Viejo, el cual comenzó a ser investigado en el año 2009 (López 2010).

Finalmente, el salar de Pocitos, se ubica hacia el Oeste de Pastos Grandes, a aproximadamente $60 \mathrm{~km}$. En el borde del salar de Pocitos se registraron distintos abrigos rocosos, pero uno de ellos se destaca por tener una posible secuencia a lo largo del Holoceno. El sitio fue denominado Abrigo Pozo Cavado, por el lugar en el que se lo detectó en la campaña de marzo de 2010 (López 2010). Por lo tanto, la investigación en este sitio recién está comenzando, pero será importante para el estudio del cambio cultural a nivel regional en comparación con otros sitios.

\section{El sitio Alero Cuevas, Pastos Grandes}

Este sitio se ubica a una altura de $4400 \mathrm{msnm}$, en la quebrada de Las Cuevas, $10 \mathrm{~km}$ hacia el Norte del poblado de Pastos Grandes. Se trata de un alero de 19,3 m de extensión y 8,7 m de profundidad hasta la línea de goteo. La excavación de 7 cuadrículas de 1 x $1 \mathrm{~m}$ y 2 sondeos de $0,5 \times 0,5 \mathrm{~m}$, permitió registrar una larga secuencia de ocupaciones humanas, que comenzaron en el Holoceno temprano (López 2009). La quebrada en la que se ubica el alero, presenta agua permanente procedente de los nevados de Pastos Grandes y recursos asociados como pasturas y fauna (por ej. camélidos), lo que hace atractivo este sector para la ocupación humana. Sin embargo, en la actualidad, la quebrada de Las Cuevas no registra ocupaciones humanas, lo cual se debe a la ubicación del poblado de Pastos Grandes en torno a la vega 


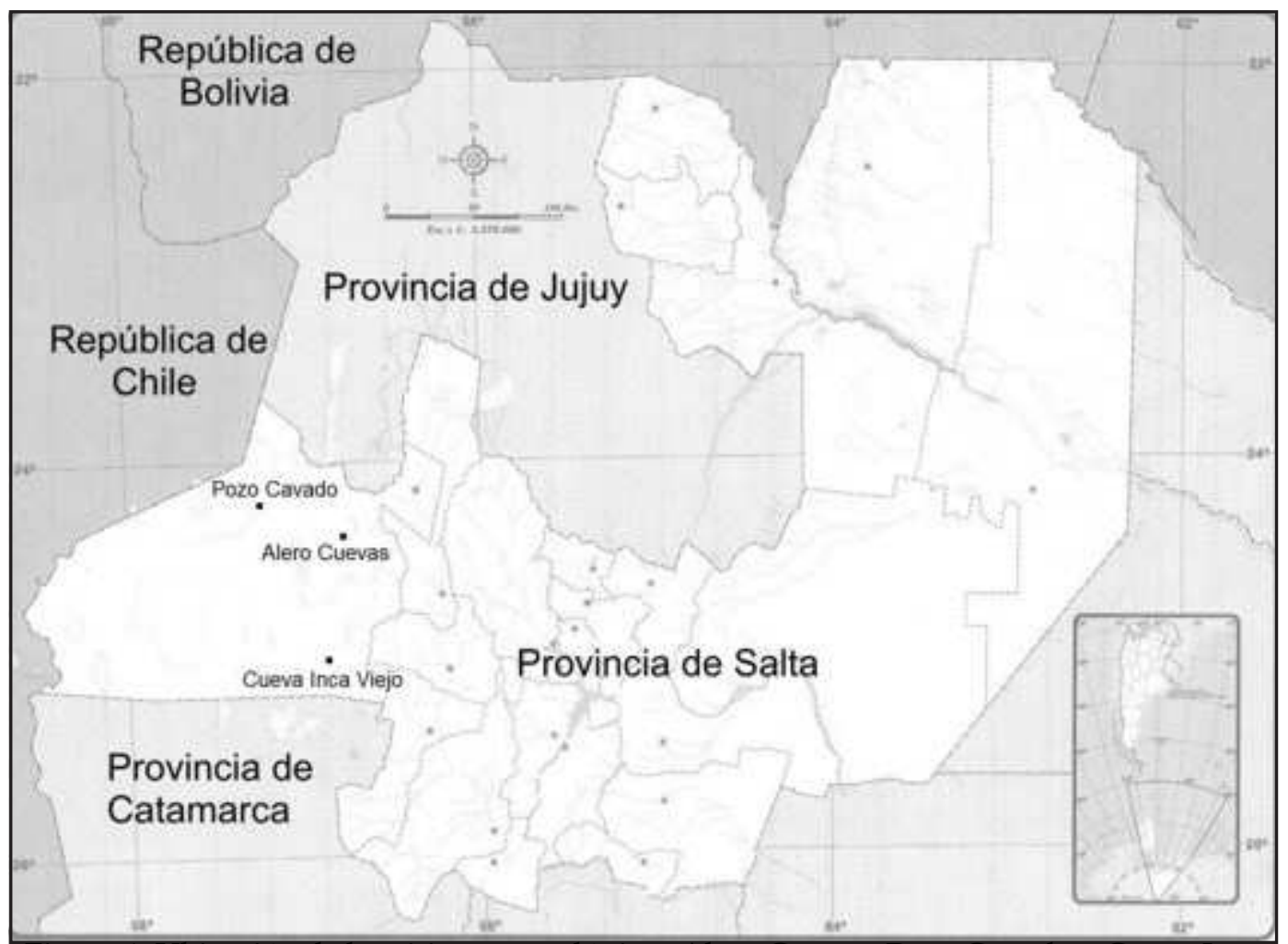

Figura 1: Ubicación de los sitios arqueológicos Alero Cuevas, Pozo Cavado y Cueva Inca Viejo en el contexto regional

principal del fondo de cuenca. Sólo la quebrada de Santa Rosa, de la cual la quebrada de las Cuevas es tributaria, es usada estacionalmente para el pastoreo.

El sitio Alero Cuevas presenta una capa inicial de guano no consolidado, producto de los burros que viven en las quebradas sin ningún control humano, aunque ocasionalmente algunos de ellos son usados para transportar algún tipo de carga. Esta capa amortigua y a su vez preserva las capas arqueológicas que se encuentran por debajo. Entre ellas, la más tardía es una capa de guano consolidado bastante discreta en la estratigrafía, que fue fechada en $643 \pm 35$ años AP (para un detalle de todos los fechados ver López 2009). Más abajo se registró una capa de paja prácticamente continua a lo largo de las 7 cuadrículas excavadas, fechada en $\mathbf{2 0 2 0} \pm \mathbf{6 0}$ años AP. Podría tratarse de un lugar para acondicionar el suelo y realizar actividades domésticas como tareas culinarias, a juzgar por la presencia de fogones estructurados. Asimismo, es relevante la alta frecuencia y diversidad de material arqueológico. Entre los conjuntos de esta capa, se recuperó óseo predominantemente de camélido, lítico (por ej. puntas triangulares pedunculadas chicas), cerámica especialmente de tonalidades oscuras y con pulido, vegetales (por ej. cordeles, esteras, agujas, astiles, marlos de maíz, etc) y valvas trabajadas (posiblemente una de ellas proveniente del Océano Pacífico).

Otra capa, fechada en $\mathbf{4 2 1 0} \pm \mathbf{7 0}$ años AP, se destaca por determinadas características de la evidencia arqueológica. En particular, cabe mencionar la presencia de tecnología laminar asociada a unos artefactos denominados "lanceolados unifaciales", no evidenciados en otras capas (López 2009). El cambio tecnológico que implica la presencia de más de 10 
especímenes (enteros y fragmentados) de esta clase artefactual junto con al menos un núcleo de hojas, también fue evidenciado en contextos de superficie tanto de Pastos Grandes como del salar de Pocitos. Esta tecnología también se destaca en el sitio Ramadas en San Antonio de los Cobres, fechado hacia fines del Holoceno medio (Muscio 2004). En cuanto a las arqueofaunas, algunos cambios osteométricos pueden relacionarse con la transición a contextos pastoriles, aunque por el momento la evidencia no permite ser concluyente (ver López 2008). Por último, es importante remarcar la alta frecuencia de hallazgos y la depositación intensa de sedimentos y materiales arqueológicos en esta capa, especialmente teniendo en cuenta que en algunos sectores la potencia de la misma es de alrededor de $30 \mathrm{~cm}$. Actualmente se encuentran en proceso otros fechados.

Por debajo de esta capa, se registró otra conformada por fragmentos de roca del alero con dos fechados que indican ocupaciones humanas discretas: $6510 \pm 80$ años AP y $6506 \pm 58$ años AP. También el registro arqueológico es reducido comparativamente con otras capas, presentando escasos artefactos formatizados, entre los que se encuentran algunas puntas y preformas lanceoladas. Los especímenes óseos corresponden especialmente a camélidos (ver López 2008).

La capa más profunda está compuesta de limo húmedo, y presenta 3 fechados: $9650 \pm 100$ años AP, $8838 \pm 52$ años AP y $8504 \pm 52$ años AP. Estos fechados la sitúan en el Holoceno temprano, y constituyen la cronología más temprana registrada hasta el momento en la Puna de Salta. Entre el registro lítico, se destaca la presencia de puntas triangulares apedunculadas, comunes en otros contextos de la Puna (Aschero y Martínez 2001). El registro arqueofaunístico presenta una representación mayoritaria de especímenes de camélidos (López 2008).

En suma, el sitio Alero Cuevas constituye una base de referencia para el estudio del cambio cultural a lo largo del Holoceno en la Puna de Salta y en las tierras altas surandinas en general.

\section{El sitio Cueva Inca Viejo, salar de Ratones}

Este sitio se ubica en los cerros que rodean hacia el Norte el salar de Ratones y hacia el Este el salar de Centenario. Se trata de una cueva profunda, constituida por distintas oquedades y galerías que continúan adentro del cerro y cuya magnitud es inestimable. La cueva se ubica a $4312 \mathrm{msnm}$ y su entrada se encuentra hacia el salar de Ratones con un ancho de boca de $6,3 \mathrm{~m}$. La cueva principal presenta una amplia galería, con $13 \mathrm{~m}$ de profundidad hacia la línea de goteo. Lo más llamativo, es la presencia en la cueva principal y especialmente hacia la boca de entrada, de distintos paneles de pinturas rupestres. Se trata de pinturas principalmente de camélidos y antropomorfos, aunque también hay figuras geométricas. Los camélidos se presentan en general en escenas vinculadas a prácticas de pastoreo y posiblemente tráfico caravanero, ya que mayormente se encuentran alineados y atados, y guiados por un antropomorfo. Esto es común en contextos tardíos asociados al tráfico caravanero (Aschero 2000, Martel y Aschero 2007). La asociación de estas representaciones de camélidos con prácticas pastoriles y potencialmente tráfico caravanero permite realizar un acercamiento temporal a la realización de las pinturas. Igualmente se debe tener en cuenta que no se evidencian llamas con carga como en los sitios del Alto Loa u otras regiones (ver Berenguer 1999). También hay imágenes de camélidos copulando, lo cual 
podría vincularse con prácticas relacionadas a la fertilidad (Aschero 2007). En cuanto a las figuras geométricas, se destaca un círculo de color negro con bordes de color rojo. Estos colores son predominantes en todas las representaciones.

Se realizaron 3 sondeos de $0,5 \times 0,5 \mathrm{~m}$ para establecer la continuidad estratigráfica y obtener muestras para fechar. Hasta el momento se detectaron dos capas arqueológicas, la inicial y la capa 1. En ambas el material arqueológico es adscribible cronológicamente a momentos pastoriles tempranos y tardíos. En el nivel 1, se halló cerámica oscura pulida común en contextos "formativos tempranos". El material orgánico se encuentra en excelente estado de preservación, tanto el arqueofaunístico como el vegetal. Preliminarmente, entre las arqueofaunas es predominante la representación de camélidos. Con respecto a los vegetales, también de manera preliminar, se recuperaron cordeles, fragmentos de astiles de caña, posibles activadores de fuego, y entre el material comestible, maíz, poroto y maní. Lamentablemente, por debajo de estas capas, la presencia de bloques de piedra de la cueva, de distintos tamaños, impidió la continuidad de la excavación en los distintos sondeos. Esto porque su continuidad en profundidad es alta. Por este motivo, se hicieron pruebas de pala en distintos sectores, sin poder llegar al final de esta capa estéril. Si bien podría ser producto de desprendimientos del techo del alero, no se descarta que por debajo de esta capa o en determinados sectores de la cueva pueda haber ocupaciones humanas precerámicas. Esto sería importante teniendo en cuenta la posibilidad de comparar con el sitio Alero Cuevas, ubicado a $80 \mathrm{~km}$ del sitio del salar de Ratones.

También se destaca el hallazgo en alta frecuencia de plumas de distintas aves. Entre ellas hay de color verde y rosado, las primeras probablemente correspondientes a aves de tierras bajas y las segundas a flamencos, los cuales se evidencian en los distintos salares de la Puna de Salta.

\section{Abrigo Pozo Cavado, salar de Pocitos}

Salar de Pocitos es un área que comenzó a ser investigada recientemente, dado que anteriormente presentaba un "vacío" de información arqueológica (López 2010). Las prospecciones realizadas en las campañas de noviembre de 2009 y marzo de 2010, permitieron reconocer distintos sitios arqueológicos, entre ellos el Abrigo Pozo Cavado. Este sitio se denomina así por el lugar en que se encuentra, un sector ubicado al Noroeste del salar de Pocitos, caracterizado como un valle amplio con cerros que lo rodean en dirección Oeste - Este. En este sector se extiende el salar de Pocitos hasta el límite Norte con el salar de Rincón. El sitio Abrigo Pozo Cavado se ubica en un sector sobreelevado de una formación de tierra limo-arcillosa en el borde del salar de Pocitos o más claramente, una extensión de tierra rodeada por el salar. El abrigo se trata en realidad de una formación rocosa con distintos aleros y reparos ubicados en forma continua a lo largo de este afloramiento. La altura es más baja que en los otros sitios mencionados en este trabajo, rondando los $3700 \mathrm{msnm}$. La prospección en el talud de este abrigo arrojó el hallazgo de una alta frecuencia de material arqueológico, principalmente relacionado a contextos de cazadores recolectores precerámicos, aunque también hay evidencia relacionada a contextos más tardíos. Entre el material más temprano, en el borde del salar se recuperaron puntas de morfología lanceolada, hojas y también algunos artefactos lanceolados unifaciales, todas características compartidas con la capa de fines del Holoceno medio del sitio Alero Cuevas. 
En la campaña de marzo de 2010 en la cual se detectó este sitio, se realizó un sondeo de $0,5 \times 0,5 \mathrm{~m}$ con el objetivo de ver las características estratigráficas y obtener muestra para fechar. El sondeo se realizó abajo de un sector del abrigo que se ubica hacia el lado Oeste del salar. En este sector, desde la pared del alero a la línea de goteo hay 2,25 m.

La capa inicial es de limo húmedo, con más de $15 \mathrm{~cm}$ de profundidad. La evidencia arqueológica constó de material óseo, desechos de talla y vegetal, principalmente marlos de maíz. Por debajo de esta capa, se registró una camada de paja de alrededor de $9 \mathrm{~cm}$ de espesor, también con material arqueológico. Sin embargo, la continuidad de la estratigrafía indicó la presencia de una capa aparentemente estéril, con grandes bloques de roca cristalizada (roca salitrosa), lo que podría señalar algún evento natural que impidió la ocupación humana, lo cual podrá ser determinado con estudios futuros. Esta capa tiene una profundidad de aproximadamente $15 \mathrm{~cm}$.

Por debajo de la capa rocosa, nuevamente se registró una capa de limo húmeda que continúa hasta los $80 \mathrm{~cm}$ de profundidad, sin haber llegado a esa altura a la roca de base. La continuidad de la excavación en una próxima campaña servirá para llegar al final de la estratigrafía. La última capa, se caracteriza por corresponder a un sector de fogón, con mucho carbón y óseo. Allí se recuperó una punta lanceolada chica, de obsidiana gris (no local), asociada con especímenes óseos.

Los indicadores arqueológicos en superficie y en capa permiten señalar este abrigo como potencialmente vinculado a ocupaciones humanas en una secuencia cronológica amplia, desde cazadores precerámicos hasta contextos pastoriles. Esto permitirá comparar la evidencia de Pozo Cavado con la del Alero Cuevas y quizás con la de Cueva Inca Viejo. De esta manera, los fechados en proceso y la continuidad de las excavaciones serán indispensables para abarcar problemáticas en escala regional.

\section{Conclusión}

En este trabajo se resumió brevemente la información arqueológica en abrigos en tres áreas de la Puna de Salta. En dos de ellas, Pocitos y Ratones, las investigaciones recién están comenzando, por lo que mucha de la información obtenida está en proceso de análisis. La comparación con el sitio Alero Cuevas y más generalmente con el registro arqueológico de Pastos Grandes es el objetivo a futuro. De todas maneras, fechados en proceso en esta área y la continuidad de las investigaciones servirán para ampliar el conocimiento obtenido hasta el momento.

La necesidad de investigar en una escala regional amplia surgió de la posibilidad de establecer conexiones arqueológicas entre ocupaciones humanas en distintas áreas de la Puna salteña. Entre ellas, cabe destacar que en Pastos Grandes, la materia prima predominante en los artefactos líticos del sitio Alero Cuevas es la obsidiana proveniente de Quirón, cuya fuente se ubica en la cuenca del salar de Pocitos. Por lo tanto, las conexiones sociales entre ambas áreas se reflejan en la evidencia arqueológica. Incluso existen problemáticas particularidades que deben analizarse en una escala regional. Por ejemplo, el cambio en el uso de la materia prima hacia un aumento en la andesita local a fines del Holoceno medio en Pastos Grandes, en relación con la proliferación de artefactos lanceolados unifaciales y tecnología de hojas. En el salar de Pocitos, al menos en superficie, ha comenzado a observarse la asociación de lanceoladas y hojas, aunque esto está sujeto a nuevas prospecciones. 
Para concluir es importante destacar que problemáticas tales como reducción de la movilidad residencial, aumento de la complejidad social, domesticación de camélidos, interacciones sociales y uso de materias primas, deben ser abarcadas en escala regional. La información proveniente de abrigos de distintas áreas va en esa dirección, por ser los sitios con mejor preservación de secuencias temporales amplias para analizar el cambio cultural. De todas maneras, la conjunción de información en superficie y en capa, en abrigos y a cielo abierto, es el camino a seguir.

\section{Agradecimientos}

Agradecemos a todas las personas que nos ayudaron durante las campañas. A Cecilia Mercuri por su participación en la campaña de noviembre de 2009 y a todos los pobladores de Pastos Grandes y Pocitos, y a Mario y todos los trabajadores mineros que luchan por la dignidad y muestran un ejemplo de vida en comunidad y solidaridad.

Este trabajo fue posible gracias al CONICET.

\section{Bibliografía citada}

Aschero, C.

2000 Figuras humanas, camélidos, y espacios en la interacción circumpuneña. En Arte en las rocas. Arte rupestre, menhires y piedras de colores en Argentina, editado por M. Podestá y M. de Hoyos, pp. 15-44. Sociedad Argentina de Antropología y Asociación Amigos del Instituto Nacional de Antropología y Pensamiento Latinoamericano. Buenos Aires

2007 Íconos, Huancas y complejidad en la Puna sur Argentina. Producción y circulación prehispánicas de bienes en el sur andino. Compilado por A. Nielsen, M. Rivolta, V. Seldes, M. Vázquez y P. Mercolli, pp. 135-166, editorial Brujas. Córdoba

Aschero, C. y J. Martínez.

2001 Técnicas de caza en Antofagasta de la Sierra, Puna Meridional Argentina. Relaciones de la Sociedad Argentina de Antropología XXVI: 215- 241.

Berenguer, $\mathrm{J}$.

1999. El evanescente lenguaje del arte rupestre en los Andes Atacameños. En Arte rupestre en los Andes de Capricornio, pp. 9-56. Museo Chileno de Arte Precolombino.

López, G.

2008 Arqueología de Cazadores y Pastores en Tierras Altas: Ocupaciones humanas a lo largo del Holoceno en Pastos Grandes, Puna de Salta, Argentina. BAR S1854, South American Archaeology Series 4, Oxford.

2009 Diversidad arqueológica y cambio cultural en Pastos Grandes, Puna de Salta, Argentina, a lo largo del Holoceno. Relaciones de la Sociedad Argentina de Antropología XXXIV: 149-176. 2010 Arqueología regional en la Puna de Salta: primeras aproximaciones al estudio de los salares Centenario, Ratones y Pocitos. Actas del XVII Congreso Nacional de Arqueología Argentina, Mendoza. En prensa.

Martel, A. y C. Aschero

2007 Pastores en acción: Imposición iconográfica vs. Autonomía temática. Producción y circulación prehispánica de bienes en el sur andino, compilado por A. Nielsen, M. Rivolta, V. Seldes, M. Vázquez y P. Mercolli, pp. 329-350. Editorial Brujas. 
Muscio, $\mathrm{H}$.

2004 Dinámica Poblacional y Evolución Durante el Período Agroalfarero Temprano en el Valle de San Antonio de los Cobres, Puna de Salta, Argentina. Tesis Doctoral, Facultad de Filosofía y Letras, Universidad de Buenos Aires. 